\title{
Perspectives on Politics Editors' Report 2019
}

\author{
Michael Bernhard, Editor in Chief \\ Daniel O'Neill, Associate Editor and Book Review Editor \\ Jennifer Boylan, Managing Editor
}

T

his year's annual report covers the journal's operations from January 1 to December 31, 2019. The end date marks two years and seven months into our four-year agreement with the association to edit Perspectives on Politics. As in previous reports, we discuss this year's editorial and technical developments, and report summary statistics on a number of important areas including submissions, editorial decision making, impact, and the book review section.

In June 2020, the journal will enter its fourth year of operation at the University of Florida. We are considering the possibility of extending our tenure an additional two years. That decision will ultimately be made by the association. We continue to have a highly constructive relationship with both the APSA offices in Washington, DC, and Cambridge University Press. We thank both organizations for their ongoing support and counsel. We continue to consistently fulfill our page budgets and hit all publication deadlines due to the diligence of the managing editor and our editorial assistants, as well as the crack production team at Cambridge. ${ }^{1}$ We have accumulated an extensive inventory of accepted front end material (articles and reflection essays) that will carry us through the next calendar year.

\section{CONTINUED THEMATIC GROUPING OF ARTICLES}

The publication of thematically-linked articles and reflections as special issues and special sections has been one of the hallmarks of the journal under our editorship. This year saw our first experiment in soliciting material for a special issue through a call for papers come to fruition. It was remarkably successful; the call for papers for "Trump: Causes and Consequences" brought in over 130 submissions and yielded material sufficient for two issues (17:2 and 17:3). We were pleased at the subfield diversity of the submissions and the published materials. While we had a large number of American politics articles, there were political theory, comparative, and international relations offerings as well. We also had several items which entailed cooperation between authors from different subfields, and by comparativists who applied theories of regime change and stability to the American case.

We continue to assemble special sections in an ad hoc fashion from pieces that were submitted by individual authors. The move to FirstView last year has made this easier, because we can publish articles online while waiting for kindred material earlier in the publication process to move into production. In addition to the Trump issues, we also published a special section on "Issues in Qualitative Research" and "Perspectival Political Theory." The special issues and sections for 2019 are summarized in table 1 with links to their respective tables of contents.

The introduction to the special section on "Perspectival Political Theory" included a programmatic discussion of the kind of work in the subfield of political theory that the journal has published and will continue to publish under associate editor Daniel O'Neill. Perspectives remains committed to a variety of approaches to political theory, so long as the scholarship is problem-driven and focused on matters of broad public concern, as befits the journal's role as the "political science public sphere." As with all our offerings, we will continue to emphasize the need for authors to selfconsciously think in broader terms about the import of their work, and to express their arguments in language that is free from subfield-specific jargon. Our goal is to ensure that the political theory articles we publish-like all others-are broadly accessible to the discipline as a whole, as well as to the wider reading public. In this way, we also hope to generate cross-field dialogue within political science, and between political scientists and the world of politics.

Our second call for papers on "Celebrity and Politics" was originally intended to yield a special section, but again the response was so positive that it yielded a special issue. The lead in this effort was taken by one of our editorial board members, Samantha Majic, who suggested the topic and served as guest editor. While the number of submissions was smaller, a few dozen, all subfields were represented.
The results of her efforts published as issue 18(1), the first in 2020. The issue is exceedingly diverse in terms of the content and the range of methods deployed.

At least two other special sections are planned for 2020. In issue 18(2) there will be a three-article section entitled "Whither America?" which addresses the question of whether the current age of populism and polarization are the new normal in American politics or a temporary detour. Finally, issue 18(3) will include several articles that explore the different ways in which violence figures in politics ("The Uses of Violence"). ${ }^{2}$

\section{PUBLICITY STRATEGIES}

\section{Embargo Dates}

With our full transition to FirstView publication for articles and reflections, we now also only publish material with fixed publication dates, so that every author knows the precise date of publication ahead of time. These "embargoed" dates are set about 10-14 days prior to publication, at which time the authors of a manuscript or reflection are sent an email alerting them to the publication date, informing them about our publicity efforts, and urging them to coordinate their own publicity efforts with ours. Our hope is that this coordinated release strategy will help our authors reach the broadest possible audience for their work.

\section{Email Addresses Added to Book Reviews}

We have worked with Cambridge to add author email addresses to all book reviews. This allows us to inform the author of the review once it has published. Previously, book review authors were told in what issue their review would publish, and that practice continues, but, unlike articles and reflections, authors were not informed once the book review actually appeared online. With the introduction of email addresses on reviews, that problem is now addressed.

\section{Twitter}

When we first took control of the Perspectives Twitter account (@PoPpublicsphere) in 2017, we had just over 1,00o followers. As of Feb 25th, 2019 the number of followers 


\begin{tabular}{lll}
$\begin{array}{l}\text { Table } 1 \\
\text { Special Sections in Volume } 17 \text { (2019) }\end{array}$ & \\
Number & Special Section & Link to Table of Contents \\
\hline $17(1)$ & Issues in Qualitative Research & https://tinyurl.com/tu3qenh \\
\hline $17(2)$ & Trump: Causes and Consequences & $\underline{\text { https://tinyurl.com/s8grasp }}$ \\
\hline $17(3)$ & Trump: Causes and Consequences (The Sequel) & https://tinyurl.com/wbbnphh \\
\hline $17(4)$ & Perspectival Political Theory & https://tinyurl.com/tdtslg6 \\
\hline
\end{tabular}

Table 2

\section{Manuscript Submissions per Year}

\begin{tabular}{ccc} 
Year & New Manuscripts Received & Revised Manuscripts Received \\
\hline 2019 & 356 & 94 \\
\hline 2018 & 316 & 101 \\
\hline 2017 & 294 & 83 \\
\hline 2016 & 321 & 51 \\
\hline 2015 & 258 & 53 \\
\hline 2014 & 253 & 47 \\
\hline
\end{tabular}

Table 3

Number of Manuscripts Received Based on the Location of the Corresponding Author

\begin{tabular}{ccc} 
Year & United States & Outside of United States \\
\hline 2019 & $190(53.8 \%)$ & $163(46.2 \%)$ \\
\hline 2018 & $181(57.3 \%)$ & $135(42.7 \%)$ \\
\hline 2017 & $164(56.6 \%)$ & $126(43.4 \%)$ \\
\hline 2016 & $190(59.9 \%)$ & $127(40.1 \%)$ \\
\hline 2015 & $155(60.8 \%)$ & $100(39.2 \%)$ \\
\hline 2014 & $170(67.5 \%)$ & $82(32.5 \%)$ \\
\hline
\end{tabular}

has risen to 2,957. We tweet about all FirstView publications and issue publications. When authors of FirstView material are emailed about their pending publication, we request their Twitter handle (if available) and include them in our tweets.

\section{Facebook}

Our highest estimated post reach in 2019 occurred on February 14th, with an estimated 2,291 people seeing our posts announcing the online publication of $17(1)$. The next highest was 1,543 on May 13th, when Vol. 17(2) published. Since we moved fully to FirstView publication in June 2019, the reach of posts now depends more on individual articles than issue publication.

\section{TECHNICAL INNOVATIONS}

\section{Dataverse}

As of February 2019, we had published 59 datasets on our Dataverse page (https:// dataverse.harvard.edu/dataverse/perspectives). This includes 580 individual files (read.me files, replication files, datasets, etc.). As per a suggestion by board member Reşat Bayer at our 2019 APSA meeting, we contacted all authors who published in the journal prior to the creation of our Dataverse page (i.e., before Volume 17), offering them the opportunity to upload replication files to our page. We have, thus far, heard back from eight sets of authors who have expressed interest and we are continuing to work with both them and Cambridge to connect their replication files to their publication pages on Cambridge Core.

\section{Decision Letters for Reviewers}

In the name of transparency, all peer reviewers for Perspectives have had access to the reports of other readers to the authors as a matter of principle. However, in the past reviewers did not get notice when decisions were taken on submissions. From December 2019 onward we have begun to send letters informing our reviewers of final decisions on manuscripts and reminding them that they have access to all reviewer reports sent to the authors.

\section{FirstView}

In 2019 we moved to publish all articles and reflections on FirstView prior to issue publication. This necessitated clearing out our queue of accepted articles. We began that process slowly and completed the effort with our "SummerSplash" event, which we publicized with great fanfare on Twitter and Facebook. Following the SummerSplash event, we published another 23 articles on FirstView before the end of the calendar year. In total, we published 45 articles and reflections in 2019, though many of these will appear in our 2020 issues.

\section{SUBMISSIONS AND PROCESSING}

\section{Number of Submissions}

The number of submissions increased for the second year in a row in 2019 (see table 2). We received 356 new and 94 revised manuscripts. The total number processed is a new high for the journal, whereas the number of revised manuscripts dropped off slightly. The combined submissions constitute a large increase (33 more manuscript submissions) than 2018. The internationalization of the contents of the journal proceeds at pace. For the first time, the number of submissions from outside the United States exceeded $45 \%$ (see table 3 ).

We continue to publish a substantial number of authors based outside the United States. In Volume 17 (2019), 17\% of the authors were employed by universities outside the United States. This was a drop from Volume 16 (2018) of the journal, when the figure reached its all-time high (26.8\%). ${ }^{3}$ We suspect that the difference in the rates of submission and acceptance are a function of the lesser familiarity of some international colleagues with the conventions of publication in English language journals. 
The editor has taken an active role in talking to international audiences about the journal, its profile, and its submission standards. Last year, he made presentations at international meetings that attract a large number of international political scientists including the Conference on European Studies in Madrid and the World Congress of the Association for the Study of Nationalities in New York. Later this year he will also do so at the Wissentschaftszentrum Berlin für Sozialforschung (WZB-Berlin Social Science Center) and the World Meeting of the International Council for Central and East European Studies in Montreal. We also believe that the addition of a larger number of colleagues based outside the US to the editorial board may have raised our profile in certain countries and this may also help explain the rise in international submissions.

\section{Processing of Submissions}

We continue to deliver speedy and constructive reviews of submitted manuscripts. Once the editors have decided to send a manuscript for external review, we endeavor to use four reviewers. We sometimes make decisions before all reviews are in if there is a strong consensus among the initial reviews that the piece should not be published in Perspectives. Many manuscripts go through more than one revise and resubmit round before publication. We try to return to the original reviewer pool on all revise and resubmits, including reviewers who express reservations about publication and are willing to read the revisions, as we hope and expect they will. When the number of readers on revised manuscripts falls below two, we rely on board members for additional reviews. Because of the large number of referees we use and the stringency of our peer review process, we monitor all manuscripts on a weekly basis to assure timely review. Table 4 provides evidence that, on balance, we are successful in providing a timely review process. As documented in the table, since we began to edit the journal on June 1, 2017 the times to editor assignment and first decision have been shortened.

\section{Editorial Decisions}

Table 5 presents data on first round editorial decisions for 2019. We decline a large number of manuscripts without external review, because we still receive a substantial number of submissions which do not fit with the mission of the journal or are

Table 4

Average Number of Days in Review Process

\begin{tabular}{lrrrrrr} 
Stage of Review Process & $\mathbf{2 0 1 9}$ & $\mathbf{2 0 1 8}$ & $\mathbf{2 0 1 7}$ & $\mathbf{2 0 1 6}$ & $\mathbf{2 0 1 5}$ & $\mathbf{2 0 1 4}$ \\
\hline Submission to Editor Assignment & 0.5 & 0.7 & 4.8 & 6.9 & 6.3 & 6 \\
\hline Submission to First Decision & 39.0 & 38.3 & 46.0 & 42.1 & 45.9 & 51.8
\end{tabular}

Table 5

First Round Editorial Decisions 2019

\begin{tabular}{llll} 
Editor Decision & $\begin{array}{l}\text { Total } \\
\text { Decisions }\end{array}$ & $\begin{array}{l}\text { Frequency of } \\
\text { Decision }\end{array}$ & $\begin{array}{l}\text { Average Time } \\
\text { to Decision (days) }\end{array}$ \\
\hline Decline (No External Review) & 191 & $55.8 \%$ & 13 \\
\hline Decline (After External Review) & 90 & $26.3 \%$ & 77.7 \\
\hline Major Revision & 49 & $14.3 \%$ & 84.8 \\
\hline Minor Revision & 10 & $2.9 \%$ & 89.8 \\
\hline Conditional Accept & 2 & $0.6 \%$ & 88 \\
\hline Total Editor Decisions & $\mathbf{3 4 2}$ & $\mathbf{1 0 0 \%}$ & $\mathbf{4 3}$ \\
\hline
\end{tabular}

not of sufficient academic quality. Of the 151 submissions that went out for external review (up from 123 last year), only 40\% ( $18 \%$ of the total submissions) were given an opportunity to revise for publication. The vast majority of revision decisions were qualified as major by the editors. The data in table 5 shows two manuscripts conditionally accepted on the first round. These were both article manuscripts that were sent out for review, rejected, and then, after considerable work with the editors based on the reviewer reports, condensed into reflection essays. No manuscript was published without at least one round of minor revisions last year.

We continue to publish the vast majority of manuscripts given a revision decision on the first round. After the first round, only eight were rejected when reviewers did not approve of the changes the authors implemented and the editors agreed with this assessment. Thirty-three manuscripts were accepted for publication in 2019, as compared to 40 in 2018. Twenty still do not have a final decision because they are being revised by their authors.

Table 6 compares this year to the previous five. APSA has asked us to try to reduce the number of "decline (no external review)" (or "desk reject") decisions. We have made progress on this issue-reducing the percentage from the recent high of 69.6\% in 2015 under the Indiana University editorial team to $55.8 \%$ this year. More manuscripts are now declined through external review (over one quarter in 2018 and 2019, substantially up from the figures under our predecessors).

Our ability to make editorial decisions is based on the generosity of our colleagues in the discipline and neighboring fields of study. While the number of reviewers who declined to review increased in 2019, from 381 to 438 , we still received 679 completed reviews for front-end manuscripts. Furthermore, of the reviews we received, about $60 \%$ of them were completed on-time. We are grateful to those who wrote reviews for sharing their time and expertise. We also thank those who, despite the personal or professional obligations that kept them from writing a review, recommended others who could replace them. These thoughtful suggestions also helped to facilitate our work.

\section{Journal Impact}

The Thomson-Reuters Journal Citation Reports two-year and five-year impact factors, as well the journal's relative standing in the discipline for the last six years, are presented in table 7 . The two-year impact factor (JIF2) measured by Clarivate Analytics shows a moderate recovery from its substantial decline last year. Our JIF2 increased from 1.714 to 2.326 from 2017 to 2018, improving our disciplinary ranking from 53 rd to 39 th. Our five-year impact factor registered a slight uptick to 3.617 , 
though that represented a drop from 19th to 23 rd in the discipline.

The JIF 2 for 2018 was based on volumes 14 and 15 published in 2016 and 2017. Next year marks the first year in which the journal's impact will include a substantial number of articles developed by the University of Florida editorial team.

\section{The Book Review Section}

As we noted last year, we consider the book review section to be as important a core mission of the journal as the publication of articles and reflections. Perspec- tives serves as the book review of record for the discipline. A review in the journal serves as notice of a book's significance and the review itself can serve as important evidence in both hiring, as well as promotion and tenure decisions. We receive far more books than we can review, as we only have space to review $350-375$ of them in any given year. We give precedence to first books from junior scholars, university press books, and books likely to make an important impact on the discipline. We do our best to use the various book review formats in the journal to encourage schol-

Table 6

\begin{tabular}{lrrrrrr}
$\begin{array}{l}\text { Outcome of First Round of the Review Process, 2014-19 } \\
\text { (percentage) } \\
\text { Outcome }\end{array}$ & $\mathbf{2 0 1 9}$ & $\mathbf{2 0 1 8}$ & $\mathbf{2 0 1 7}$ & $\mathbf{2 0 1 6}$ & $\mathbf{2 0 1 5}$ & $\mathbf{2 0 1 4}$ \\
\hline Decline (No External Review) & 55.8 & 59.2 & 59.4 & 69.1 & 69.6 & 64.9 \\
\hline Decline (After External Review) & 26.3 & 26.1 & 25.5 & 22.3 & 19.2 & 22.9 \\
\hline Major Revision & 14.3 & 12.4 & 10.4 & 5.5 & 7.2 & 7.4 \\
\hline Minor Revision & 2.9 & 1.6 & 2.7 & 2.8 & 4 & 3.9 \\
\hline Conditional Accept & 0.6 & 0.7 & 0.3 & 0.3 & 0 & 0.4 \\
\hline Accept & 0 & 0 & 1.7 & 0 & 0 & 0.4 \\
\hline
\end{tabular}

Table 7

Journal Impact Factor, 2013-18

\begin{tabular}{lllll} 
Year & $\begin{array}{l}\text { 2-Year } \\
\text { Impact Factor }\end{array}$ & $\begin{array}{l}\text { Political Science } \\
\text { Rank (annual) }\end{array}$ & $\begin{array}{l}\text { 5-Year } \\
\text { Impact Factor }\end{array}$ & $\begin{array}{l}\text { Political Science } \\
\text { Rank (5-year) }\end{array}$ \\
\hline 2018 & 2.326 & $39 / 176$ & 3.617 & $23 / 166$ \\
\hline 2017 & 1.714 & $53 / 169$ & 3.607 & $19 / 166$ \\
\hline 2016 & 3.234 & $8 / 165$ & 3.68 & $7 / 161$ \\
\hline 2015 & 2.462 & $10 / 163$ & 3.257 & $6 / 156$ \\
\hline 2014 & 2.132 & $11 / 161$ & 2.661 & $16 / 153$ \\
\hline 2013 & 3.035 & $2 / 157$ & 2.628 & $9 / 142$ \\
\hline Source: Clarivate Analytics. InCites Journal Citation Reports. https://jcr.incites.thomsonreuters.com/JCRJournalHomeAction.action
\end{tabular}

Table 8

Book Reviews Published in Volume 17 (2019)

\begin{tabular}{llllll} 
Field & $\begin{array}{l}\text { Conventional } \\
\text { Reviews }\end{array}$ & $\begin{array}{l}\text { Review } \\
\text { Essays }\end{array}$ & $\begin{array}{l}\text { Critical } \\
\text { Dialogues }\end{array}$ & Symposia & Total \\
\hline International Relations & 56 & 1 & 11 & 1 & 69 \\
\hline American & 74 & 0 & 4 & 1 & 79 \\
\hline Theory & 72 & 1 & 7 & 0 & 80 \\
\hline Comparative & 74 & 1 & 8 & 0 & 83 \\
\hline Total & $\mathbf{2 7 6}$ & $\mathbf{3}$ & $\mathbf{3 0}$ & $\mathbf{2}$ & $\mathbf{3 1 1}$ \\
\hline
\end{tabular}


their way to help us, relying on their long experience in journal publication. ${ }^{4}$ The APSA office in Washington, DC, and the leadership of the association continue to be consistently supportive of our efforts to improve the journal. We appreciate their counsel and willingness to work with us to better serve the members of the American Political Science Association. ${ }^{5}$

\section{NOTES}

1. Our work would not be possible without the committed and careful work of our editorial assistants. In 2019 they were Alec Dinnin, Peter Licari, Karla Mundim, Marah Schlingensiepen, Dragana Svraka, Stephanie Denardo, and Saskia van Wees.

2. Many of these articles are already available on FirstView. Interested readers can peruse them here: https://www.cambridge.org/core/journals/ perspectives-on-politics/firstview

3. The balance between male and female authorship in volume 17 was $60 \%$ to $40 \%$ (based on lead author). This is a slight drop in female authorship from volume 16 (54.75\% to $45.25 \%$ ). Issue $17: 2$, the first of the Trump special issues was strongly out of balance ( $87.5 \%$ male lead authorship). The other three issues in this volume were much more balanced (52\% male lead authorship).

4. We would like to express our gratitude to Mark Zadrozny, David Mainwaring, Katrina Swartz, Wendy Moore, Jim Ansell, Alyssa Neumann, Molly Sheffer, Andrew Hyde, Linda Lindenfelser, Gavin Swanson, and Gail Naron Chalew.

5. We would also like personally to thank Rogers M. Smith, Steven R. Smith, Jon Gurstelle, Henry Chen, and Karima Scott for the unflagging support and counsel provided by APSA. 